\title{
Synthesis of Water-Solved Epoxy-Amine Oligomers and Receiving Coating Based on Them by Cathodic Electrodeposition
}

\author{
Yury V. Churilov*, Alina M. Dolzhanskaya, \\ Anna A. Silaeva, Nadezhda A. Rodionova, \\ Evgenia O. Tochilkina and Michael Y. Kvasnikov \\ Mendeleev University of Chemical Technology of Russia \\ Moscow, Russian Federation
}

Received 14.05.2021, received in revised form 25.05.2021, accepted 16.08.2021

\begin{abstract}
Kinetics of synthesis of epoxy-amine oligomers that are used as polielectrolytes in technology of cathodic electrodeposition was researched. Solubilityof the reaction product was researched by a correlation between $\mathrm{pH}$ and amount of neutralizing agent, molar mass distribution was researched for confirmation of expected molar mass. Pigment paste in three different options was made and used in a mixture with binder emulsion to receive coatings deposited on a cathode. Their properties were researched.
\end{abstract}

Keywords: epoxy-amine oligomers, electrodeposition, synthesis.

Citation: Churilov, Yu. V., Dolzhanskaya, A. M., Silaeva, A. A., Rodionova, N. A., Tochilkina, E. O., Kvasnikov M. Y. Synthesis of water-solved epoxy-amine oligomers and receiving coating based on them by cathodic electrodeposition, J. Sib. Fed. Univ. Chem., 2021, 14(3), 360-370. DOI: 10.17516/1998-2836-0244

(C) Siberian Federal University. All rights reserved

This work is licensed under a Creative Commons Attribution-NonCommercial 4.0 International License (CC BY-NC 4.0).

* Corresponding author E-mail address: yuriychurilov@gmail.com 


\title{
Синтез водорастворимых эпоксиаминных олигомеров
}

\author{
и получение покрытий на их основе \\ методом катодного электроосаждения
}

\author{
Ю. В. Чурилов, А.М. Должанская, А. А. Силаева, \\ Н. А. Родионова, Е. О. Точилкина, М.Ю. Квасников \\ Российский химико-технологический университет \\ им. Д.И. Менделеева \\ Российская Федерация, Москва
}

\begin{abstract}
Аннотация. Исследована кинетика синтеза эпоксиаминных олигомеров, применяемых в технологии катодного электроосаждения полиэлектролитов. Проведено исследование растворимости продукта реакции по зависимости $\mathrm{pH}$ от количества добавленного нейтрализующего агента и исследование молекулярно-массового распределения для подтверждения ожидаемого диапазона молекулярной массы. Из продукта реакции была приготовлена пигментная паста в трех различных вариациях, которую использовали вместе с эмульсией связующего для получения лакокрасочных покрытий, осаждаемых на катоде. Были исследованы их свойства.
\end{abstract}

Ключевые слова: эпоксиаминные олигомеры, электроосаждение, синтез.

Цитирование: Чурилов, Ю. В. Синтез водорастворимых эпоксиаминных олигомеров и получение покрытий на их основе методом катодного электроосаждения / Ю. В. Чурилов, А. М. Должанская, А. А. Силаева, Н. А. Родионова, Е. О. Точилкина, М.Ю. Квасников // Журн. Сиб. федер. ун-та. Химия, 2021, 14(3). С. 360-370. DOI: 10.17516/1998-2836-0244

\section{Введение}

Эпоксиаминные олигомеры являются одним из возможных пленкообразователей, применяемых в технологии катодного электроосаждения полиэлектролитов. Механизм формирования покрытий этим методом связан с потерей растворимости полиэлектролита в зависимости от значений $\mathrm{pH}$, меняющегося на электродах при электролизе воды, электрофоретическим осаждением наполнителей и пигментов, а также с электроосмотическим обезвоживанием образующегося осадка. Достоинствами данного метода признаны его экономичность, экологичность, пожаробезопасность, а также возможность использовать электроосаждение для нанесения покрытий на участки изделий сложной конфигурации, которые невозможно качественно окрасить другими методами. Кроме того, покрытия, образующиеся с помощью этого метода, однородны по толщине. Эти достоинства сделали его практически незаменимым в крупномасштабных автоматизированных производствах при грунтовании корпусов автомобилей, бытовых приборов и других металлических изделий.

Для придания покрытиям на основе эпоксиаминных олигомеров специальных свойств применяются различные химические модификации. Для улучшения адгезии, эластичности и коррозионной стойкости покрытий в качестве пленкообразователя применяют эпоксидную смолу, модифицированную глицидиловыми эфирами [1-9]. Также возможна модифика-

$$
-361-
$$


ция пленкообразователями на основе капролактона, к примеру капролактамом [10]. Наиболее простой способ модификации эпоксидного олигомера заключается во введении в структуру карбоксильных или гидроксильных соединений с длинной алифатической цепью, например жирных кислот, полиэфиров, фенолов и алкилфенолов, в результате чего образуются эфирные и сложноэфирные группы $[11,12]$. В качестве второго компонента для синтеза эпоксиаминного олигомера зарубежные патенты и литература рекомендуют использовать вторичные амины, содержащие гидроксильные группы [1-2, 13]. Их использование может положительно сказаться на свойствах покрытия за счет увеличения функциональности системы, что приведет к возрастанию степени сшивки при формировании трехмерного полимера. Также увеличение полярных гидроксильных групп обеспечит стабильность водных растворов из-за повышенного содержания гидроксильных групп $[1,8,12]$.

Целью данной работы является получение водорастворимых эпоксиаминных олигомеров и исследование процесса их синтеза. Для того чтобы материал для катодного электроосаждения осаждался на катоде, эпоксиаминный олигомер переводят в водорастворимое состояние за счет взаимодействия аминных групп аддукта с уксусной кислотой, получаемые системы применяют при рН от 4 до 6.

\section{Экспериментальная часть}

\section{Исходные вещества}

Выбранными исходными компонентами для создания эпоксиаминного олигомера являются эпоксидная смола со средней молекулярной массой от 380 до 500, чему соответствует смола ЭД-20 (ГОСТ 10587-84) или аналоги (смола NPEL-128S фирмы NanYaPlasticsCorp (Тайвань), смола Epicot 1001 фирмы HexionInc, (США), смола CHS-Eроху 520 фирмы Spolchemie (Чехия), и вторичный амин - диэтаноламин.

Схема реакции представлена на рис. 1.

\section{Методика эксперимента}

Реакция аминного соединения с эпоксидной смолой должна протекать в таком эквимолярном соотношении, чтобы получившийся продукт мог полностью растворяться в воде при допировании кислотой. Для обеспечения полноты протекания реакции предпочтительно держать реакционную смесь в диапазоне температур между 70 и 130 градусов. После проведения

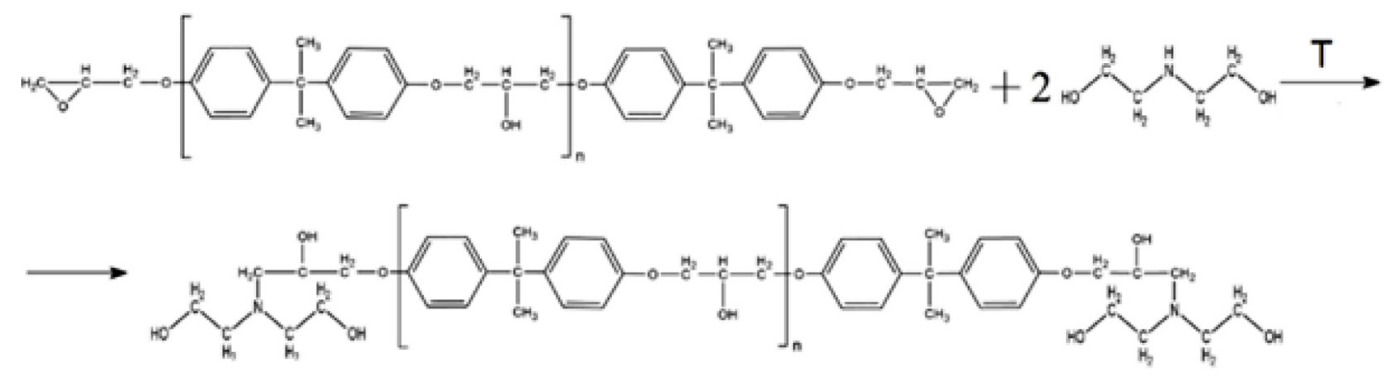

Рис. 1. Схема реакции ЭД-20 и ДЭА

Fig. 1. Scheme of a recation ED-20 and DEA 
синтеза необходимо использовать экстракцию или вакуумную отгонку для удаления из системы растворителя и непрореагировавшего амина [14].

Количественно ход реакции контролировали с помощью определения эпоксидного числа по ГОСТ 56752-2015. Исследования эпоксидного числа по данному стандарту для смол с содержанием аминов проводятся методом обратного титрования [15]. В ходе синтеза от реакционной массы отбирали пробы каждые 15 мин и проводили их анализ на содержание эпоксидных групп.

Для проведения дальнейших исследований проводили синтез эпоксиаминного олигомера из ЭД-20 и диэтаноламина в растворителе - этилгликоле при $70{ }^{\circ} \mathrm{C}$. ИК-спектр исходного эпоксидного компонента представлен на рис. 2.

ИК-спектр получен с использованием спектрометра ИК-Фурье Nicolet 380 ThermoScientific.

Как видно на рис. 2, эпоксидный компонент характеризуется наличием связанной ОН-группы у немодифицированной ЭД-20 в диапазоне 3300-2500 см-1, которая представляет собой широкую полосу или группу полос, часто способную перекрываться валентными колебаниями С-Н, в частности в диапозоне колебаний 3100-3000 см-1 [16].

ММР эпоксиаминного олигомера определяли методом гель-хроматографии на приборе Agilent 1260 InfinityII.

Получение покрытий проводили на лабораторной установке для катодного электроосаждения с ванной объемом 0,5 л при следующих показателях рабочего раствора ЛКМ: $\mathrm{pH}=5,5$; сухой остаток $14-15$ мас.\%, $\mathrm{T}=27-32{ }^{\circ} \mathrm{C}$. В качестве анода использовали нерастворимый анод из нержавеющей стали 08X10H20T (AISI303). Режим электроосаждения при постоянном напря-

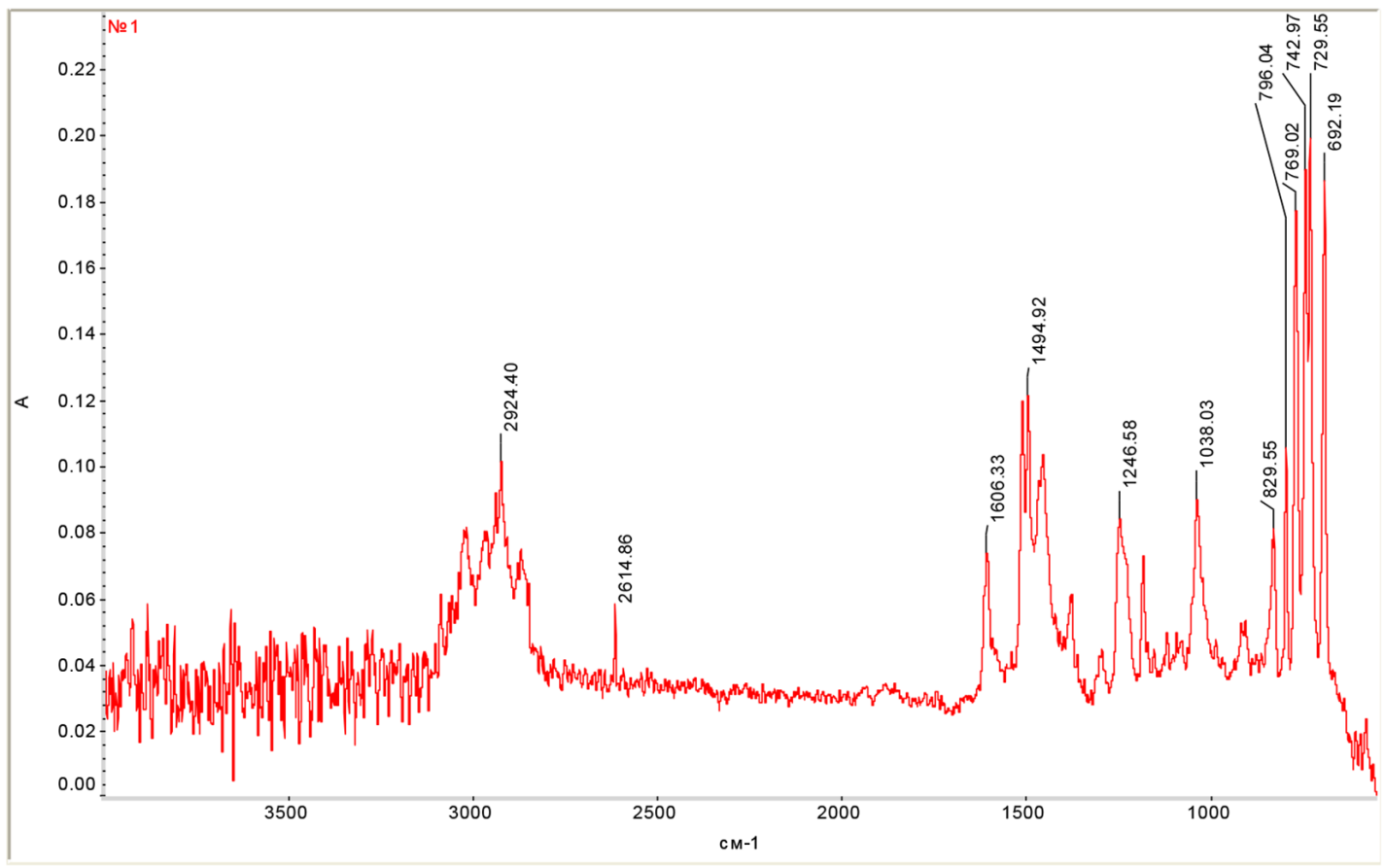

Рис. 2. ИК-спектр ЭД-20 в ксилоле

Fig. 2. IR-specter ED-20 in xylene 
жении в диапазоне 120-240 В и продолжительности 120 с. Катодами служили металлические пластины из стали 08КП (AISI A622) площадью 0,2 дм², обезжиренные и подготовленные согласно требованиям ISO 1513. Для формирования готовых покрытий требовалось термоотверждение электроосажденных осадков, которое проводили при температуре $180{ }^{\circ} \mathrm{C}$ в течение 20 мин. В указанных условиях формировались бездефектные ровные покрытия, удовлетворяющие по внешнему виду ISO 4628 (ГОСТ Р 51691-2008).

Для определения свойств покрытий использовались стандартные методики, принятые в лакокрасочной технологи: толщина покрытия определялась по ГОСТ Р 51694-2000 (ISO 2808), адгезия - по ГОСТ 31149-2014 (ISO 2409), сопротивление быстрой деформации (сопротивление удару) - по ГОСТ Р 53007-2008 (ISO 6272), эластичность (прочность при изгибе) - по ГОСТ Р 52740 (ISO 1519), твердость - по ГОСТ Р 54586-2011 (ISO15184), блеск - по ГОСТ 31975-2017.

\section{Результаты и обсуждения}

По результатам определения эпоксидного числа в ходе синтеза был получен кинетический график реакции эпоксидной смолы ЭД-20 и диэтаноламина, представленный на рис. 3.

Реакция аминной группы с эпоксидными группами описывается кинетическим уравнением первого порядка. Методом подстановки нами подтверждено, что кинетические параметры исследуемой реакции соответствуют реакциям первого порядка - линейная форма кинетического графика представлена на рис. 4. Константа скорости $\mathrm{k}_{\text {образец } 1}=0,0624$ мин $^{-1}[17,18]$.

ИК-спектр образовавшегося эпоксиаминного олигомера представлен на рис. 5.

Увеличение интенсивности пика колебаний гидроксильных групп в диапазоне 3300 2500 см-1 обусловлено образованием ОН-групп в ходе реакций эпоксидных групп с аминами, а также гидроксильными группами диэтаноламина [16].

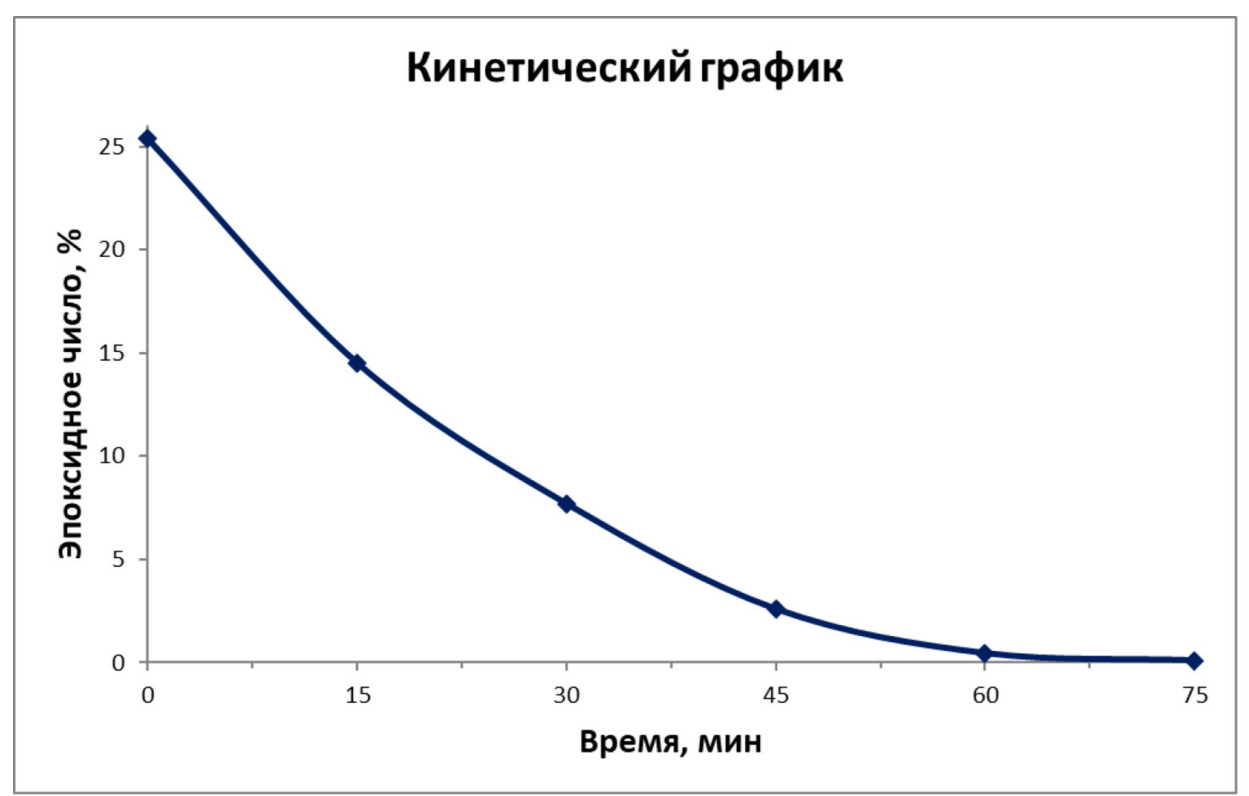

Рис. 3. Кинетический график реакции эпоксидной смолы и ДЭА

Fig. 3. Kinetic graph of a reaction between epoxy resin and DEA 


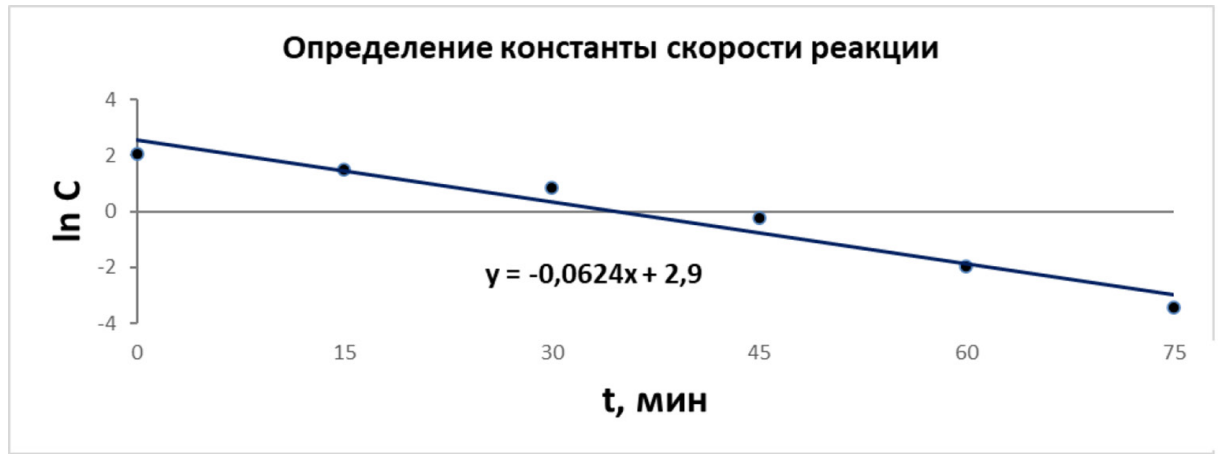

Рис. 4. Линейная форма кинетического графика $\ln C(\mathrm{t})$

Fig. 4. Linear form of a kinetic curve $\ln \mathrm{C}(\mathrm{t})$

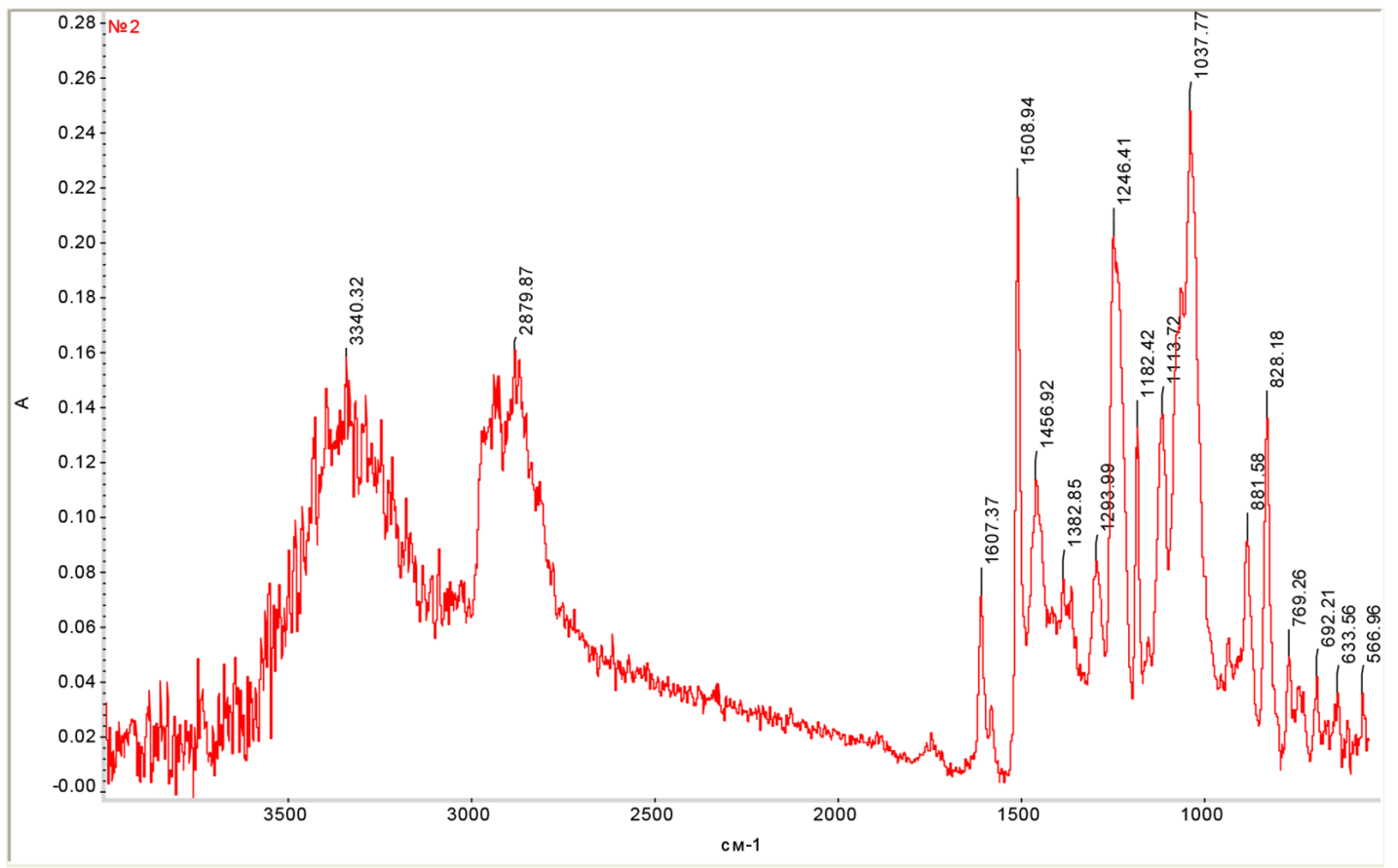

Рис. 5. ИК-спектр эпоксиаминного олигомера

Fig. 5. IR-specterofepoxy-amineoligomer

Качественным показателем полного протекания реакции служит растворимость эпоксиаминного олигомера в воде. Гидрофильные свойства проявляются при нейтрализации аминных групп уксусной кислотой.

График зависимости рН от количества добавленной уксусной кислоты для образца 1 представлен на рис. 6.

Видно, как и предполагалось, что граница растворимости находится в диапазоне рН вокруг 7 [19]. Различный вид кривой растворимости до и после $\mathrm{pH} 7$ объясняется разными механизмами, протекающими в растворе при различной концентрации кислоты. Так, при рН от 9,85 


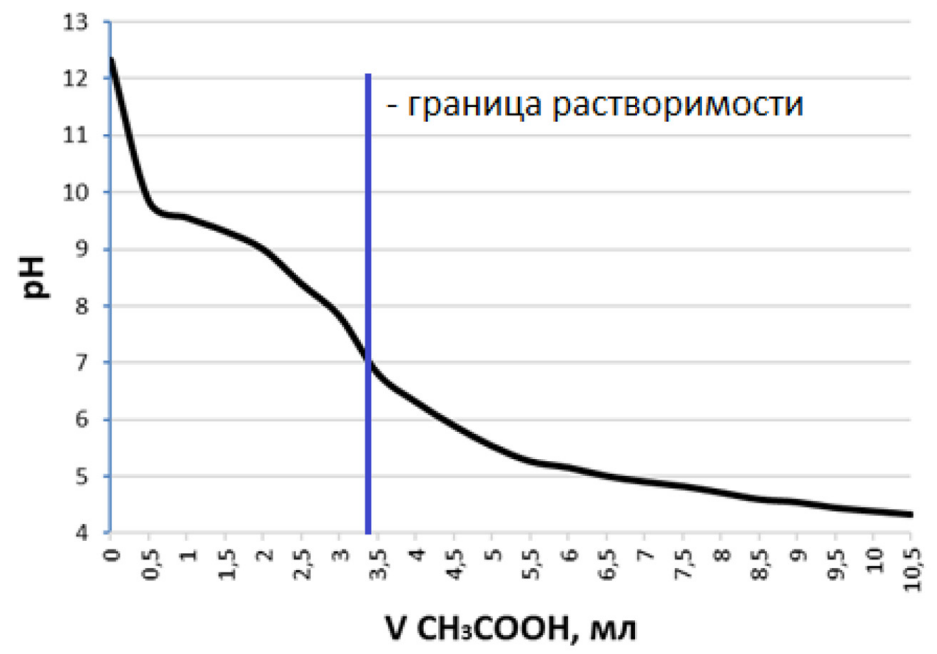

Рис. 6. График зависимости $\mathrm{pH}$ от количества уксусной кислоты

Fig. 6. Graph of a correlation between $\mathrm{pH}$ and amount of acetic acid

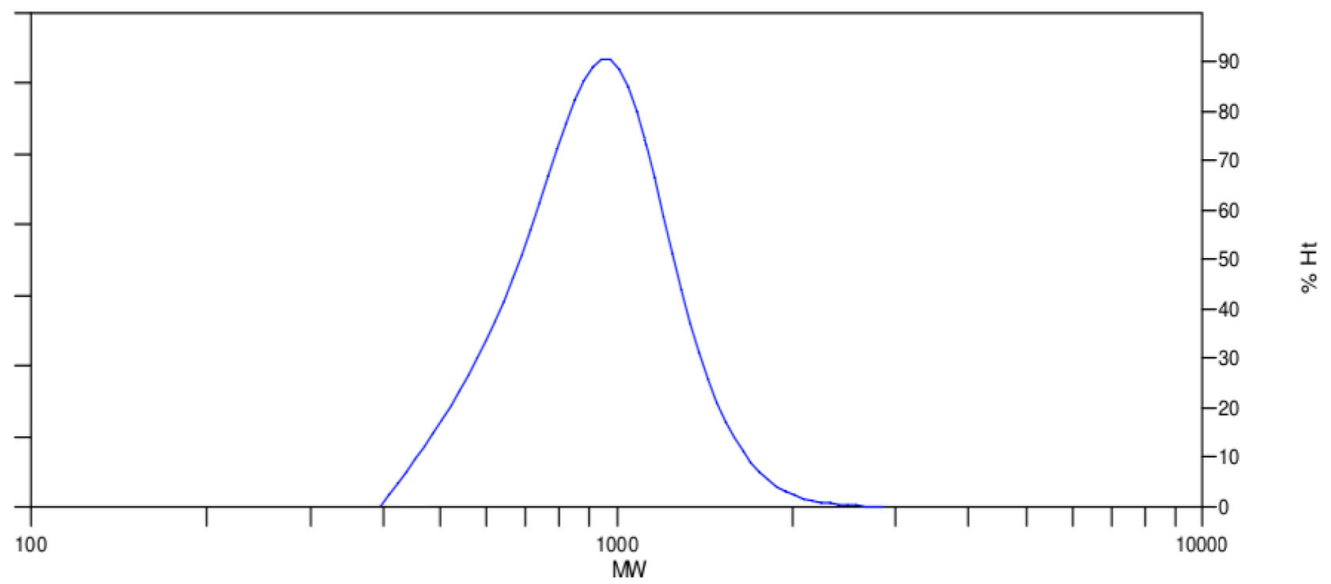

Рис. 7. ММР полученного эпоксиаминного олигомера

Fig. 7. Molar mass distribution of received epoxy-amine oligomer

до 7 происходит процесс растворения олигомера в водной среде, что объясняется характером кривой, схожим с кинетическим графиком неограниченного набухания [20]. При $\mathrm{pH}$ меньше 7 кривая приобретает вид кинетического графика. Это объясняется образованием аммонийных солей, что и определяет характер кривой.

График молекулярно-массового распределения (ММР) образца 1 представлен на рис. 7. Видно, что диапазон пика ММР приходится на значение 900 г/моль, что соответствует среднемолекулярным полимерам.

В результате проведенная нами реакция с получением эпоксиаминного олигомера при указанных условиях приводит к получению среднемолекулярного растворимого в воде олигомера, что соответствует нашим исходным требованиям. 
Для подтверждения возможности электроосаждения на катоде из полученного эпоксиаминного аддукта был изготовлен пигментированный материал для получения покрытий на металлических пластинках. Состав композиций указан в табл. 1.

Покрытия получали в условиях, указанных в разделе Экспериментальная часть. Свойства полученных покрытий приведены в табл. 2.

Видно, что синтезированный нами образец эпоксиаминного олигомера способен электроосаждаться на катоде. Полученные из него покрытия имеют отличную адгезию, а также отличную прочность при ударе.

\section{Выводы}

В нашей работе был описан процесс получения немодифицированного эпоксиаминного олигомера, описаны свойства полученных аддуктов, получен пигментированный материал. Доказана химическая природа полученных веществ, способность полученных материалов осаждаться на катоде и формировать покрытия, обладающие защитными и декоративными свойствами. В дальнейших исследованиях планируется изучить процесс эмульгирования эпоксиаминного аддукта и блокированного изоцианата в водной среде, а также продолжить изучение пигментных паст на основе синтезируемого эпоксиаминного аддукта.

Таблица 1. Состав композиций для электроосаждения

Table1. Composition of solution for electrodeposition

\begin{tabular}{|l|c|c|c|}
\hline & Композиция 1 & Композиция 2 & Композиция 3 \\
\hline Пленкообразующее & $\begin{array}{c}\text { Эпоксиаминный } \\
\text { олигомер }\end{array}$ & $\begin{array}{c}\text { Эпоксиаминный } \\
\text { олигомер }\end{array}$ & $\begin{array}{c}\text { Эпоксиаминный } \\
\text { олигомер }\end{array}$ \\
\hline Допирующий агент & Уксусная кислота & Уксусная кислота & Уксусная кислота \\
\hline Пигмент & Технический углерод & Технический углерод & Технический углерод \\
\hline $\begin{array}{l}\text { Соотношение получ. } \\
\text { пигм. паста: эм. связ. др. } \\
\text { производит. }\end{array}$ & $1: 60$ & $1: 30$ & $1: 15$ \\
\hline
\end{tabular}

Примечание к таблице 1: пигм. паста - пигментная паста; эм. связ. др. производит. - эмульсия связующего другого производителя.

Таблица 2.Свойства полученных покрытий

Table2. Properties of applied coatings

\begin{tabular}{|l|c|c|c|}
\hline \multicolumn{1}{|c|}{ Испытание } & Композиция № 1 & Композиция № 2 & Композиция № 3 \\
\hline Толщина, мкм & 6 & 5 & 3 \\
\hline $\begin{array}{l}\text { Блеск под углом } 20^{\circ}, \\
\text { единицы блеска }\end{array}$ & 56 & 42 & 13 \\
\hline Расход, г/м2 & 30 & 20 & 17 \\
\hline Адгезия, баллы & 1 & 0 & 0 \\
\hline Прочность при ударе, см & 100 & 100 & $>100$ \\
\hline
\end{tabular}




\section{Благодарности / Acknowledgments}

Измерения ИК-спектрометрии выполнены на оборудовании Центра коллективного пользования имени Д.И. Менделеева.

Measurements of IR-spectroscopy are carried out on the equipment of Center of Collective Usage named after D. I. Mendeleev.

\section{Список литературы / References}

1. Patent US20140262791A1 Manesh N. Sekharen, Shawn E. Dolan, Brian J. Marvin, Bashir M. Ahmed, John D. McGee, Omar L. Abu-Shanab, Derek A. Hickey. Electrodeposition of an autodepositable polymer. Publ. Date 18.09.2014

2. Ranjbara Z., Moradian S. The Effect of Molecular Weight of Epoxy Resin on the Deposition Behaviour of Water-borne Epoxy-amine Adducts. Iranian Polymer Journal 2004. No13, P. 69-75

3. Patent 6020069A US. Joseph A. Antonelli, Christopher Scopazzi. Cathodic electrocoating composition containing an epoxy resin chain extended with primary amine. Publ. Date 02.01.2000

4. Квасников М.Ю. Получение лакокрасочных покрытий методом электроосаждения. Промышленные покрытия 2018. № 3-4, C. 56-61 [Kvasnikov M. Iu. Receiving painting coatings by electrodeposition method. Industrial coatings 2018. № 3-4, P. 56-61 (In Russ.)]

5. Квасников М.Ю., Киселев М.Р., Камедчиков А.В., Точилкина Е.О. Лакокрасочные износоустойчивые композиционные покрытия с повышенной химической стойкостью, получаемые методом электроосаждения на катоде. Журнал прикладной химии 2017. Т. 90. Вып. 6, C. 713-723 [Kvasnikov M.IU., Kiselev M.R., Kamedchikov A.V., Tochilkina E.O. Painting wearresistant composite coatings applicated by method of electrodeposition on a cathode. Journal of applied chemistry 2017. V. 90. I. 6, P. 713-723 (In Russ.)]

6. Kvasnikov M. Yu., Kiselev M.R., Kamedchikov A. V, Tochilkina E. O. Wear-Resistant composite coatings with increased chemical resistance, produced by electrodeposition on a cathode. Russian Journal of Applied Chemistry 2017, 90(6), P. 870-879

7. Патент 2495070 РФ Квасников М.Ю., Крылова И.А., Уткина Л.А., Камедчиков А.В., Ролдугин В. И. Лакокрасочная композиция с высокой рассеивающей способностью для получения методом электроосаждения на катоде химстойких износостойких покрытий с повышенной твердостью и антикоррозионной защитой. Дата публ. 10.10.2013 [Patent 2495070 RF Kvasnikov M. Iu., Krylova I. A., Utkina L.A., Kamedchikov A. V., Roldugin V. I. Coating compositionwith high spreading ability for application chemical and wear resistant coatings with increased durability and anto-corrosion protection by electrodeposition method on a cathode. Publ. date 10.10.2013 (In Russ.)]

8. Патент 2600638 РФ Павлихин С.Е, Точилкина В.С., Квасников М.Ю., Романова О.А. Способ получения гидрофобных лакокрасочных покрытий методом анодного электроосаждения с улучшенными защитными свойствами и повышенной рассеивающей способностью. Дата публ. 03.10.2016 [Patent 2600638 RF Pavlikhin S.E., Tochilkina V. S., Kvasnikov M. Iu., Romanova O. A. Ways of receiving hydrophobic painting coatings by anodic electrodeposition method with better protection properties and increased spreading ability. Publ. date 03.10.2016 (In. Russ)]

9. Квасников М.Ю., Точилкина В. С., Рудковская Л. А., Крылова И. А., Павлихин С. Е. Современное состояние и перспективы развития метода окраски электроосаждения водоразбавляемым ЛКМ. Промышленная окраска 2008. № 4, С. 6-11. [Kvasnikov M. Iu., Tochilkina V.S., 
Rudkovskaya L. A., Krylova I. A., Pavlikhin S. E. Modern condition and perspectives of development of water-born coatings painted using electrodeposition method. Industrial painting 2008. № 4, P. 6-11 (In Russ.)]

10. Патент 2566145С2 РФ Такеси Аиба, Такеси Намото, Фумиаки Накао. Красящая композиция и способ формирования покрывной пленки с ее применением. Патентообладатель Ниссан Мотор Ко., Лтд., 2011 [Patent 2566145S2 RF Takesi Aiba, Takesi Namoto, Fumiaki Nakao. Painting composition and ways of forming covering films with it's application. Patent owner Nissan Motor Co., Ltd., 2011 (In Russ.)]

11. Brock T., Groteklaes M., Mischke P. European Coatings Handbook. Vincentz Network GmbH \& Co KG, 2000. P. 410.

12. Мюллер Б., Пот У. Лакокрасочные материалы и покрытия. Принципы составления рецептур. Москва: Пейнт Медиа, 2007. С. 237 [Muller B. Pot U. Painting materials and coatings. Principles of forming recipes. Moscow: Peint Media, 2007. P. 237. (In Russ.)]

13. WO2013089903A1 Nathan J. Silvernail, Steven D. Perrine, Michael J. Pawlik, Richard F. Karabin. Resin based post rinse for improved throwpower of electrodepositable coating compositions on pretreated metal substrates. Publ. Date 20.06.2013

14. Patent US7906002B2 Masaharu Shimoda, Eisaku Okada. Method for forming surfacetreating film. Publ. Date 15.03.2011

15. ГОСТ 56752-2015 Смолы и соединения эпоксидные. Методы определения массовой доли эпоксидных групп и эпоксидного эквивалента. Издание стандартное, Стандартинформ, Москва, 2016. [GOST 56752-2015 Epoxy resins and compounds. Definition methods of mass fraction of epoxy groups and epoxy equivalent. Standard Edition, Standartinform, Moscow, 2016 (In Russ.)]

16. Тарасевич Б.Н. ИК-спектры основных классов химических соединений. Справочные материалы. МГУ имени М.В. Ломоносова, химический факультет, кафедра органической химии, Москва, 2012 [Tarasevich B.N IR Specters of main classes of chemical compounds. Reference materials. MSU after M. V. Lomonosov, Chemical Faculty, Division of organic chemistry. Moskow, 2012 (In Russ.)]

17. Рудаков О. Б. [и др.] Контроль отверждения эпоксидной смолы по содержанию свободного бисфенола А методом ТСХ. Аналитика и контроль 2017. Т. 21(2), С. 135-143 [O. B. Rudakov [and others] Control of epoxy resin hardening by content of free bisphenol A using thin-layer chromatogtaphy. Analytics and control 2017. Vol. 21, № 2, P. 135-143 (In Russ.)]

18. Катнов В.Е. Синтез и применение аддукта фенолформальдегидного олигомера и гексаметилендиамина в качестве отвердителя эпоксидных покрытий: автореф, ... дис. канд. хим. наук: 29.03.12. Казань, 2012. 20 с. [Katnov V.E. Synthesis and application of phenolformaldehyde oligomer and hexamethilendiamine as a hardener of epoxy coatings: abstract of $\mathrm{PhD}$ in Chemistry: 29.03.12. Kazan, 2012. P. 20 (In Russ.)]

19. Чурилов Ю.В., Квасников М.Ю., Точилкина Е.О., Должанская А.М. Гидрофильные свойства эпоксиаминных смол для применения в лакокрасочной промышленности. Мaтериаль с заданными свойствами на переходе к новому технологическому укладу: химические технологии: сб. материалов II научно-технической конференции 2020. Москва: НИЦ «Курчатовский институт» ИРЕА, с. 196 [Churilov Y.V., Kvasnikov M.Y., Tochilkina E.O., Dolzhanskaya A.M. Hydrophilic properties of epoxy amine resins for application in paint and

$$
-369-
$$


coating industry. Materials with given properties on a switch to the new technological way: chemical technologies: collection of materials of the II scientific-technological conference 2020. Moscow: NRC «Kurchatov Institute» IREA, P. 196 (In Russ.)]

20. Тагер А.А. Физико-химия полимеров. Издание 4-е, переработанное и дополненное. М.: Научный мир, 2007. С. 576 [Tager A. A. Physics-chemistry of polymers. Edition 4 reedited and completed. M.: Scientific World, 2007. P. 576 (In Russ.)] 